\title{
La utilidad de los protocolos clínicos
}

\section{The usefulness of clinical protocols}

\author{
Luis Antonio Rodríguez $\mathbb{D}^{1}$ \\ ${ }^{1}$ Hospital General Docente "Roberto Rodríguez", Morón, Ciego de Ávila, Cuba
}

Recibido: 31/01/2021

Revisado: 09/02/2021

Aceptado: 09/02/2021

\section{Autor correspondiente}

Carlos Miguel Ríos-González carlosmigue rios@live.com

\section{Conflictos de interés}

El autor declara no poseer conflictos de interés.

\section{Fuente de financiación}

El autor no recibió apoyo financiero para la investigación, autoría y/o publicación de este artículo.

Este artículo es publicado bajo una licencia de Creative Commons Reconocimiento 4.0 Internacional.

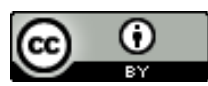

\section{Estimado editor:}

Los protocolos clínicos sin lugar a dudas constituyen una guía metodológica de inestimable valor. Estos facilitan el accionar médico permitiendo unificar criterios, experiencias y lograr mayor precisión en cuanto a diagnóstico y terapéutica. Es por ello el auge de los protocolos en la actualidad y su importancia en tiempos de COVID 19, puesto que constituyen una defensa válida ante la crítica al médico sobre una conducta tomada.

La elaboración de un protocolo puede interpretarse como un sincero y merecido homenaje a la historia de la medicina, un mensaje de aliento y esperanza a los que enarbolan con dignidad su bandera y- porque no decirlo también- el pago inacabado de una deuda de gratitud con nuestros maestros, a quienes debemos la esencia de nuestra formación médica y conocimientos acumulados.

Sin embargo, considero que su valor aumenta siempre que sean vistos como normas que orienten y no como normas rígidas de estricto cumplimiento. Considero que estos deben ser propios de cada hospital o área de salud, enriquecidos por las experiencias foráneas, adaptadas a las particularidades tecnológicas, experiencias médicas y el arsenal terapéutico de cada unidad.

Entiendo que por existir "enfermos y no enfermedades" (1) y por ser la medicina un arte y no una ciencia exacta, estos deben ser individualizados y adaptados a las características biopsicosociales de cada paciente. Lo anterior fue puesto de manifiesto por H. Boerhavve, en el siglo XVIII, al señalar "qué importa que la medicina avance, en cada enfermo en particular y valiéndose de signos particulares del mismo, siempre habrá que diagnosticar su enfermedad particular y luego efectuar el tratamiento con un especial medio de curación y con un método especial para cada paciente" (1). También pienso que estos deben ser lo suficientemente cambiantes para poder adaptarse a la velocidad con que cada día, apoyados en las nuevas tecnologías de información y comunicación, nos llegan noticias desde las más disimiles regiones del planeta de que algo ha cambiado, que ha surgido un nuevo fármaco o que sencillamente se ha demostrado por uno o varios colectivos científicos que lo que ayer constituía el proceder más acertado ante una determinada enfermedad ya no es así.

Debido a que ha surgido algo nuevo que supera lo anterior, es por ello que cada colectivo encargado de protocolizar un determinado proceder debe tener presente esta realidad para no correr el riesgo de que lo normado caiga en la desactualización y se convierta en una herramienta obsoleta y de poco valor.

Pienso que solo así los protocolos cumplirán el objetivo para el que fueron 
creados, que no puede ser otro que el de contribuir a mitigar las dolencias del hombre enfermo, siendo capaces de contribuir a devolverlo como ser útil y creador a la sociedad.

\section{REFERENCIAS}

1. Laín Entralgo P. El diagnóstico médico: historia y teoría. Barcelona: Salvat; 1982 